\title{
Produção, caracterização e aplicação de carvão ativado de caroço de pêssego no tratamento de efluente têxtil
}

\author{
Production, characterization, and application of activated \\ charcoal from peach kernel in textile effluent treatment \\ Kelly Kathleen Almeida Heylmann ${ }^{1} \oplus$, Bruno Vasconcelos Lopes ${ }^{1} \oplus$, \\ Thays França Afonso' ${ }^{\oplus}$, Carolina Faccio Demarco ${ }^{1}{ }^{\oplus}$, \\ Tito Roberto Cadaval Junior ${ }^{\top} \odot$, Maurízio Silveira Quadro' ${ }^{\oplus}$, Robson Andreazza'* ${ }^{1 *}$
}

口-

\section{RESUMO}

O objetivo deste estudo foi caracterizar a produção de um carvão de caroço de pêssego e também avaliar a adsorção de corantes têxteis pelo carvão ativado de caroço de pêssego. A ativação do carvão foi realizada utilizando cloreto de zinco como agente oxidante. O carvão ativado foi então utilizado na adsorção de corantes, para posterior aplicação no tratamento de um efluente têxtil. Primeiramente, realizou-se a produção de carvão ativado com as temperaturas de 500,700 e $900^{\circ} \mathrm{C}$ e tempo de carbonização de 1015 e 20 minutos e verificou-se a remoção dos corantes preto reativo 5 e azul de metileno. De acordo com a metodologia de superfície de resposta, a melhor temperatura de produção apresentou-se acima de $700^{\circ} \mathrm{C} \mathrm{com}$ tempo de exposição de 10 minutos para os dois corantes. Desse carvão ativado, avaliaram-se os dados de densidade, teor de umidade e cinzas, $\mathrm{pH}$ e rendimento. Também foram realizados ensaios cinéticos e de equilíbrio. Os dados foram ajustados a três modelos cinéticos. As medidas para determinação da eficiência na remoção de cor do efluente têxtil foram realizadas pelo método espectrofotométrico e demonstraram média de remoção superior a 62\% da cor presente no efluente bruto. Desse modo, o caroço de pêssego demonstrou elevado potencial para a produção de carvão ativado visando o tratamento de efluentes contendo corantes, podendo servir como alternativa de baixo custo.

Palavras-chave: carvão ativado; adsorção; corantes; efluente têxtil.
The aim of this study was to characterize the production of activated charcoal from the peach kernel and assess the adsorption of textile dyes by this activated charcoal. The activation of the charcoal was performed using zinc chloride as the oxidizing agent. The activated charcoal was then used in the adsorption of dyes for later application in the treatment of a textile effluent. Firstly, the production of activated carbon was carried out at temperatures of 500,700 , and $900^{\circ} \mathrm{C}$ and carbonization time of 10,15 , and $2 \mathrm{O}$ minutes and the removal of the Reactive Black 5 and Methylene Blue dyes was verified. According to the methodology of response surface, the best production temperature was above $700^{\circ} \mathrm{C}$ with 10 min exposure for both dyes. From this activated carbon, data on density, moisture and ash content, $\mathrm{pH}$, and yield were evaluated. Kinetic and equilibrium tests were also performed. The data were fitted to three kinetic models. The measures to determine the efficiency in the color removal of the textile effluent were carried out by the spectrophotometric method and demonstrated an average removal greater than $62 \%$ of the color present in the raw effluent. In this way, the peach kernel demonstrated a high potential for the production of activated carbon aiming at the treatment of effluents containing dyes and can serve as a low cost alternative.

Keywords: activated charcoal; adsorption; dyes; textile effluent.

\section{INTRODUÇÃO}

No Brasil, a produção de pêssego tem se expandido consideravelmente nos últimos anos, sendo o Rio Grande do Sul o maior produtor nacional (IBGE, 2019). Durante o processamento do pêssego ocorre a geração de grande quantidade de resíduos como caroços, que, muitas vezes, são descartados de forma inadequada no meio ambiente. Assim, se faz necessária a busca por alternativas sustentáveis e econômicas de descarte ou reutilização.

Nos últimos anos, houve um número considerável de estudos sobre materiais alternativos para a produção de carvão ativado a partir de resíduos agrícolas. O emprego de resíduos para a produção de carvão ativado pode reduzir

Universidade Federal de Pelotas - Pelotas (RS), Brasil.

*Autor correspondente: robsonandreazza@yahoo.com.br

Conflitos de interesse: os autores declaram não haver conflito de interesses.

Financiamento: nenhum.

Recebido: 07/07/2019 - Aceito: 29/04/2020 - Reg. ABES: 20190226 
os problemas de gestão, bem como diminuir os custos de produção e agregar valor à cadeia produtiva (KOSHELEVA; MITROPOULOS; KYZAS, 2019). Além disso, mudanças recentes nos padrões de qualidade dos efluentes têm colocado em ênfase essa tecnologia para o controle da poluição (RUIZ; FERRERALORENZO; FUENTE, 2017).

O carvão ativado tem se destacado nos processos de purificação, filtração, desodorização e separação (CRINI; LICHTFOUSE, 2019). Entre as principais características que fazem do carvão ativado um bom adsorvente, destacam-se sua grande área superficial, alta pureza, natureza microporosa, elevada capacidade de adsorção e fácil disponibilidade (GÜRSES, 2019).

O carvão ativado apresenta-se como um adsorvente universal bastante difundido e com diversas aplicações. Entre os diferentes usos, encontram-se tratamento de água, clarificação de produtos, fabricação de bebidas, purificação de gases, extração de metais, tratamentos de efluentes, usos medicinais e aplicações analíticas laboratoriais (KOSHELEVA; MITROPOULOS; KYZAS, 2019).

No tratamento de efluentes, a adsorção com carvão ativado apresenta-se como um método eficiente e relativamente de baixo custo, além de o processo de adsorção proporcionar algumas vantagens sobre os métodos clássicos de tratamento de efluentes, tais como baixa geração de resíduos, eficiente remoção de substâncias, simplicidade de operação, fácil recuperação de metais e possibilidade de reutilização do adsorvente (GUILLOSSOU et al., 2019). A habilidade de remoção de grande variedade de compostos de difícil tratamento em águas contaminadas intensifica a procura por carvão ativado de baixo custo (ODUBIYI; AWOYALE; ELOKA-EBOKA, 2012).

Com a produção mundial em alta e o uso extensivo de tintas, a descarga de efluentes contendo tais substâncias sem o devido tratamento gera graves impactos ambientais e problemas patológicos para a saúde humana, com reflexo direto na qualidade de vida da população (JAHNKE; HORNBUCKLE, 2019).

Nesse contexto, os tratamentos de efluentes industriais têxteis apresentam ineficiência na remoção dos corantes quando utilizados os métodos tradicionais. Os corantes apresentam-se como compostos aromáticos de estrutura complexa, incorporados a vários grupos funcionais, que são amplamente utilizados nas indústrias dos mais diversificados setores e, devido a tais propriedades, acabam por dificultar e encarecer o respectivo tratamento (VISWANATHAN; PERIYASAMY; KUMAR, 2019).

No uso de corantes ou pigmentos de cor, destacam-se o corante catiônico sintético azul de metileno (AM) e o corante aniônico preto reativo 5 (PR5), muito utilizados na indústria, mas que têm complexa estrutura molecular aromática. Desse modo, torna-se necessário o emprego de uma técnica eficiente para a remoção desses poluentes e a utilização do carvão ativado produzido a partir de um resíduo industrial agrícola apresenta-se como uma alternativa ambientalmente correta e eficaz para o tratamento. Assim, o presente estudo visou o aproveitamento de um resíduo sólido agrícola e industrial da região de Pelotas, por meio do emprego de caroços de pêssego na produção de carvão ativado, e, posteriormente, o estudo da sua aplicação no tratamento de efluentes têxteis.

\section{METODOLOGIA}

\section{Produção do carvão ativado}

Para a produção do carvão ativado foi utilizado como material precursor caroço de pêssego, por se tratar de um resíduo agrícola comum da região de Pelotas.
A matéria-prima empregada no estudo foi doada por empresas locais do município de Pelotas, Rio Grande do Sul, e era referente às safras 2013/2014 e 2014/2015.

A metodologia utilizada no processo de produção do carvão ativado segue uma adaptação dos trabalhos de Gonçalves et al. (2007), Oliveira (2008) e Deng et al. (2011).

Os caroços de pêssego foram lavados e expostos ao sol, para perda de umidade e não propagação de fungos. Posteriormente, foram moídos e passaram pelo processo de peneiramento com separador magnético utilizando-se uma peneira na faixa de granulometria \#10. Os procedimentos de lavagem do resíduo, ativação química e carbonização foram estabelecidos com base no estudo realizado por Niedersber (2012).

O material peneirado foi submetido ao processo de impregnação com $\mathrm{ZnCl}_{2}$, em que o material permanecia em contato dinâmico com o agente químico, para posterior carbonização. Para a impregnação, foram separados $10 \mathrm{~g}$ do material in natura e colocados em contato dinâmico em um agitador magnético Prolab 752A em temperatura ambiente durante 24 horas, com $10 \mathrm{~g}$ de $\mathrm{ZnCl}_{2}$ dissolvidos em $30 \mathrm{~mL}$ de água destilada, garantindo uma proporção de $1: 1\left(\mathrm{ZnCl}_{2} /\right.$ material $)$.

O processo de carbonização foi realizado em cadinhos de porcelana, em um forno tipo Mufla Lucadema Microprocessado LUCA 2000C-DI, sendo aplicadas diferentes faixas de temperaturas $\left(500,700\right.$ e $\left.900^{\circ} \mathrm{C}\right)$ e tempo $(10$, 15 e 20 minutos). As amostras carbonizadas foram lavadas, com uma solução de $\mathrm{HCl}$ a 2,5\%, para total eliminação dos íons de zinco e desobstrução dos poros. Após, elas foram lavadas com água destilada até obtenção do pH da água de lavagem igual ao $\mathrm{pH}$ inicial da água, então o material foi seco em estufa a $110^{\circ} \mathrm{C}$ por 1 hora.

\section{Caracterização do carvão ativado}

No carvão ativado produzido foram avaliados os dados de rendimento, umidade, densidade, cinzas e pH. A caracterização também foi realizada para o material in natura e para o carvão ativado comercial. Contudo, o rendimento foi analisado somente para a amostra com maior eficiência.

O rendimento descreve a perda do material no processo de queima e foi analisado por intermédio da pesagem das amostras in natura e após a carbonização. Para isso, as amostras foram pesadas antes e após a carbonização, para verificação do rendimento.

A umidade foi analisada por meio da secagem em estufa a $105^{\circ} \mathrm{C}$. As amostras foram colocadas em cadinhos tarados que sofreram secagem em estufa, então foram resfriados em um dessecador, tendo sua massa novamente determinada. Após, os cadinhos retornaram à estufa e esse procedimento foi repetido até a obtenção de massa constante (AOAC, 1997).

A cinza foi determinada por intermédio da incineração para remoção da matéria orgânica. As amostras foram colocadas em cadinhos de porcelana tarados na mufla em temperatura de $550^{\circ} \mathrm{C}$, por um período de 2 horas. A diferença de massa antes e após a incineração determina a concentração de cinzas da amostra (AOAC, 1997).

A densidade compreende a massa específica aparente do carvão ativado sendo determinada pela massa de amostra compactada por unidade de volume em uma pipeta volumétrica expressa em $\mathrm{g} \mathrm{cm}^{-3}$.

$\mathrm{O}$ pH da amostra foi medido segundo adaptação da norma ASTM D3838/80 descrita por Fonseca (2013). Foram pesados $5 \mathrm{~g}$ da amostra de carvão e, em seguida, adicionados $50 \mathrm{~mL}$ de água destilada. O material foi 
aquecido e mantido em ebulição por dois minutos. Após a fervura, as amostras foram filtradas com o auxílio de um funil com papel-filtro. As amostras permaneceram em repouso, para resfriar, e o $\mathrm{pH}$ foi medido com o auxílio de um pHmetro calibrado.

\section{Ensaios de adsorção}

Após a caracterização do carvão foram realizados os ensaios de adsorção. Os testes de adsorção foram realizados com soluções do corante aniônico PR5, fórmula molecular $\mathrm{C}_{26} \mathrm{H}_{21} \mathrm{~N}_{5} \mathrm{O}_{19} \mathrm{~S}_{6} \mathrm{Na}_{4}$, com comprimento de onda de $\lambda=598 \mathrm{~nm}$, e do corante catiônico AM, fórmula química $\mathrm{C}_{16} \mathrm{H}_{18} \mathrm{ClN}_{3} \mathrm{~S}_{3} \mathrm{H}_{2} \mathrm{O}$, com comprimento de onda de $\lambda=665 \mathrm{~nm}$. Para a determinação da concentração dos corantes PR5 e AM na amostra, foram realizadas curvas analíticas para cada corante, descritas na Figura 1.

Os ensaios ocorreram no jar test da marca Nova Ética, com capacidade para seis jarros com volume de $2 \mathrm{~L}$ cada. As alíquotas foram retiradas e analisadas por espectrofotômetro da marca Kasuaki em um processo de 48 horas. Os resultados foram calculados utilizando-se a Equação 1, e posteriormente a esse processo foi construída a cinética para os diferentes corantes.

$\mathrm{q}_{\mathrm{e}}=(\mathrm{Co}-\mathrm{Ce}) \mathrm{v} / \mathrm{m}$

A eficiência de remoção dos corantes PR5 e AM foi determinada por meio da Equação 2 .

Eficiência $(\%)=((\mathrm{Co}-\mathrm{Ce}) / \mathrm{Co}) 100$

Em que:

$\mathrm{Co}=$ Concentração inicial expresso em $\mathrm{mg} \mathrm{L}^{-1}$;

$\mathrm{Ce}=$ concentração do composto expresso em $\mathrm{mg} \mathrm{L}^{-1}$;

$\mathrm{v}=\mathrm{o}$ volume expresso em $\mathrm{L}$;

$\mathrm{m}=\mathrm{a}$ massa do carvão expresso em $\mathrm{g}$.
A cinética de adsorção foi analisada para os modelos de Pseudoprimeira ordem, Pseudossegunda ordem e Elovich. O equilíbrio foi avaliado para os modelos de isotermas de Langmuir e Freundlich.

\section{Ensaios de adsorção com efluente real}

Após a determinação do ajuste do modelo cinético e isoterma, o carvão ativado produzido foi avaliado no tratamento de um efluente têxtil. $\mathrm{O}$ efluente, coletado após o processo de equalização, foi proveniente do processo de tingimento utilizando corantes reativos para tingimento de fios da estação de tratamento de efluentes (ETE) de uma indústria têxtil. O efluente foi tratado com carvão ativado produzido em Erlenmeyer a $40^{\circ} \mathrm{C}$ sob agitação constante. O efluente tratado após 24 horas foi filtrado em kitassato a vácuo e após foram feitas as leituras via espectrofotômetro UV-Visível Shimadzu. Considerando-se os valores de absorbância dos efluentes não tratado e tratado com o carvão ativado produzido, calculou-se o percentual de eficiência do tratamento.

A determinação da remoção da cor do efluente foi realizada conforme a metodologia descrita por Kammradt (2004) para efluentes têxteis que apresentam forte coloração, com base na norma DIN EN ISO 7887/1994 (ISO, 1994). A metodologia se aplica a amostras que não apresentam um valor máximo de absorbância definido, comum em efluentes da indústria têxtil com uma banda de absorbância desde 370 até $800 \mathrm{~nm}$. O objetivo do tratamento do efluente têxtil com carvão ativado produzido foi a remoção da cor presente, para posterior reaproveitamento de água no processo de tingimento de tecidos dentro da indústria.

\section{Análise estatística}

Os resultados obtidos de eficiência e da caracterização das amostras foram avaliados pela análise de variância, sendo aplicado posteriormente o teste de Tukey, para comparar as médias de cada determinação, a 5\% de probabilidade. Os resultados foram analisados com o auxílio dos softwares Statistic 7.0
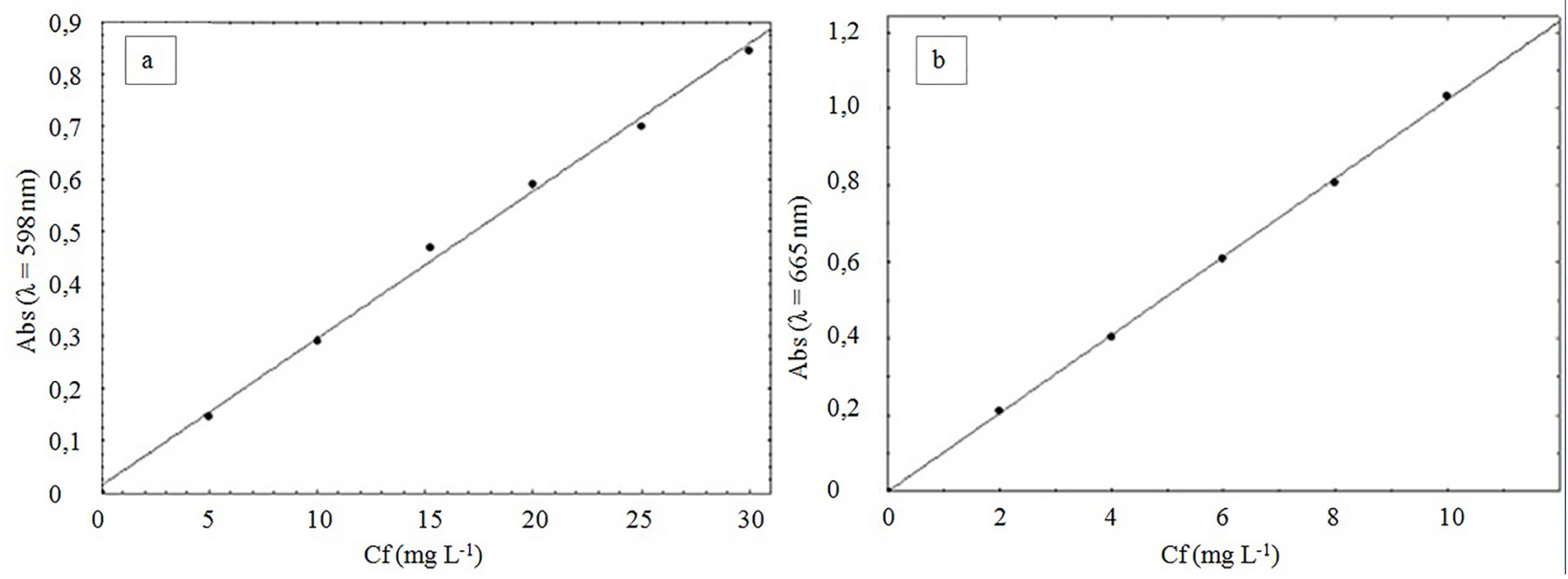

Fonte: elaborada pelos autores.

Figura 1 - Curva analítica do corante (A) Preto Reativo $5\left(y=0,0281 x+0,0143\right.$ e $\left.R^{2}=0,9971\right)$ e curva analítica do corante (B) Azul de Metileno ( $y=0,1024 x-0,0016$ e $\mathrm{R}^{2}=0,9998$ ). 
(STATSOFT, Estados Unidos) e Sigma Plot (SYSTAT, Alemanha). É importante ressaltar que as amostras foram realizadas em triplicata, para maior confiabilidade do processo, e que todas as amostras passaram pelo processo de peneiramento respeitando a NBR 12075 (ABNT, 1991b).

\section{RESULTADOS E DISCUSSÃO}

Os testes de adsorção com diferentes temperaturas e tempos de exposição empregados na produção do carvão ativado de caroço de pêssego apresentaram diferentes resultados para a metodologia de superfície de resposta (Figuras 2 e 3 ).

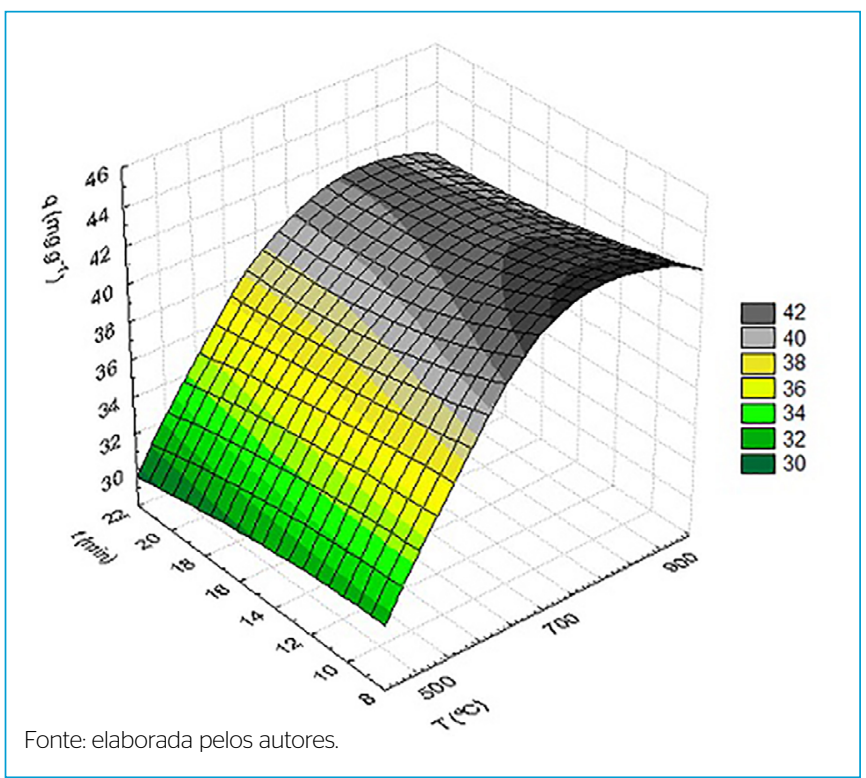

Figura 2 - Superfície de resposta do carvão ativado produzido diferentes temperaturas e tempos de carbonização para remoção do corante PR5.

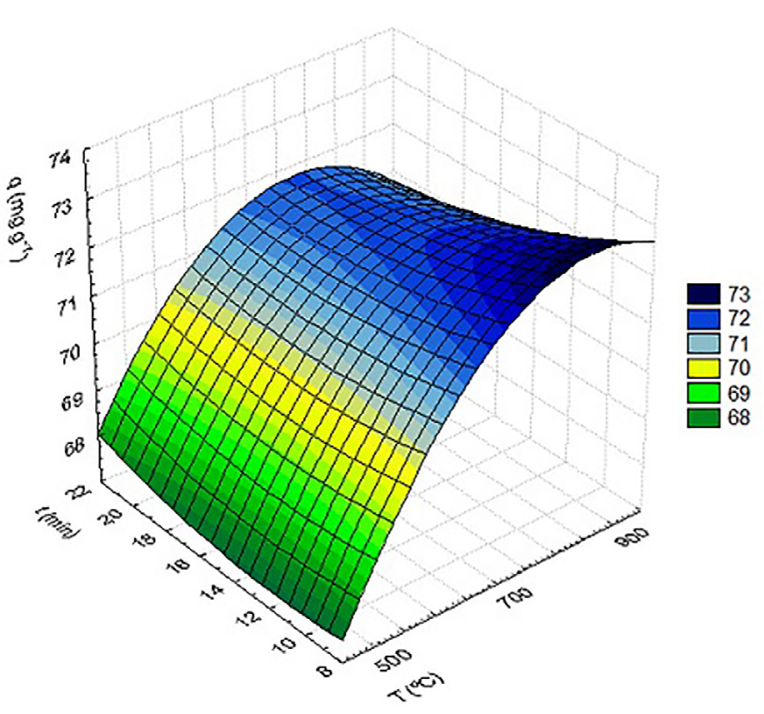

Fonte: elaborada pelos autores.

Figura 3 - Superfície de resposta do carvão ativado produzido em diferentes temperaturas e tempos de carbonização para remoção do corante AM.
Isso ocorre devido ao fato de que durante a produção do carvão ativado há fatores que influenciam na eficiência adsortiva, tais como tempo, temperatura, natureza do material precursor, fluxo de gás de arraste e taxa de aquecimento empregado (AHMADPOUR, 1996).

Dessa forma, com o objetivo de obter a máxima eficiência no processo, foram empregados diferentes tempos e temperaturas no processo de carbonização, a fim de compreender seu efeito na eficiência do carvão ativado produzido. A superfície de resposta demonstrou que o melhor tratamento foi com a carbonização realizada durante 10 minutos com temperatura superior a $700^{\circ} \mathrm{C}$, em que os resultados mostraram capacidade adsortiva de $42 \mathrm{mg} \mathrm{g}^{-1}$, o equivalente a 54,8\% de eficiência de remoção do corante PR5 (Figura 2).

Os melhores índices de adsorção para o corante AM (Figura 3) encontram-se também para o tempo de processo de 10 minutos, período que apresentou valores de quantidade adsorvida de $73 \mathrm{mg} \mathrm{g}^{-1}$, representando, desse modo, eficiência de remoção superior a $80 \%$ do corante da solução.

A adsorção do corante AM obteve menor variação do tempo de 10 minutos em relação ao tempo de 15 minutos, não apresentando diferença significativa na adsorção. Observa-se também que há tendência de aumento da remoção do corante de acordo com a redução do tempo de carbonização para as temperaturas mais elevadas, pois a amostra apresentava perda de capacidade adsortiva em função do maior tempo de exposição no forno.

A maior eficiência e sustentabilidade na realização do carvão ativado produzido utilizando-se caroços de pêssego como material precursor optou-se pela temperatura de $700^{\circ} \mathrm{C}$ durante o tempo de exposição no forno de 10 minutos. A temperatura de $700^{\circ} \mathrm{C}$ apresentou pouca variação para o mesmo carvão produzido a temperatura de $900^{\circ} \mathrm{C}$; dessa forma, a produção do carvão em menor temperatura significa redução do gasto energético, reduzindo, assim, também o seu custo.

Na produção de carvão ativado a partir de resíduos agrícolas, como noz de macadâmia, semente de goiaba e caroço de pêssego utilizando $\mathrm{ZnCl}_{2}$, foram empregadas temperaturas superiores a $700^{\circ} \mathrm{C}$ (ROCHA, 2006; OLIVEIRA, 2008). Contudo, nosso trabalho demonstrou que a temperatura de $700^{\circ} \mathrm{C}$ obteve alta remoção dos corantes em estudo e que também, pelo menor gasto de energia elétrica, é a melhor eficiência energética e técnica.

A temperatura empregada no processo relaciona-se diretamente com as características do carvão ativado produzido, pois a porosidade tende a aumentar de acordo com a temperatura de pirólise, seguindo a tendência geral observada para diferentes materiais precursores (DUFOURNY et al., 2019).

Com o interesse de caracterizar o carvão ativado escolhido a partir da metodologia de superfície de resposta, foram analisados os dados de densidade, teor de umidade, cinzas e $\mathrm{pH}$. O rendimento obtido para a produção do carvão ativado de caroço de pêssego foi de $25,96 \pm 1,51 \%$. A caracterização também foi realizada para os diferentes materiais utilizados no processo produtivo e para o carvão ativado comercial (Tabela 1).

O procedimento de análise das propriedades químicas do carvão, como o pH e a natureza da superfície, apresentam-se como importantes ferramentas na identificação das propriedades do carvão ativado que estão sendo determinantes no processo de adsorção.

$\mathrm{O}$ pH apresenta grande influência na adsorção em solução, pois determina a carga da superfície e coordena as interações eletrostáticas entre o adsorvato e o adsorvente. O denominado ponto de carga zero ( $\mathrm{pHpcz}$ ) é o valor de 
Tabela 1 - Propriedades físico-químicas do material in natura (caroço de pêssego em natura), carvão (caroço carbonizado e não ativado), $\mathrm{CA} 700^{\circ} \mathrm{C}^{*} \mathrm{e} \mathrm{CA}$ Comercial (carvão ativado comercial).

\begin{tabular}{l|c|c|c|c} 
Amostra & $\begin{array}{c}\text { Densidade } \\
\left(\mathbf{g} / \mathrm{cm}^{3}\right)\end{array}$ & $\begin{array}{c}\text { Umidade } \\
(\%)\end{array}$ & $\begin{array}{c}\text { Cinzas } \\
(\%)\end{array}$ & $\mathrm{pH}$ \\
\hline In natura & $1,73 \pm 0,03$ & $13,71 \pm 0,13$ & $0,38 \pm 0,26$ & $4,05 \pm 0,54$ \\
\hline Carvão & $0,36 \pm 0,02$ & $4,12 \pm 0,12$ & $1,23 \pm 0,01$ & $5,14 \pm 0,26$ \\
\hline CA (700 $\mathrm{C})$ & $0,39 \pm 0,02$ & $8,58 \pm 0,32$ & $2,73 \pm 0,68$ & $6,14 \pm 0,26$ \\
\hline CA Comercial & $0,43 \pm 0,04$ & $6,32 \pm 0,64$ & $2,08 \pm 0,27$ & $8,78 \pm 0,32$ \\
\hline
\end{tabular}

${ }^{*} \mathrm{O}$ CA $700^{\circ} \mathrm{C}$ refere-se ao carvão ativado selecionado de acordo com os melhores resultados obtidos para a remoção do corante PR5 e AM, tendo sido produzido com carbonização de 10 minutos a $700^{\circ} \mathrm{C}$.

Fonte: elaborada pelos autores.

pH necessário para que a superfície do adsorvente apresente carga neutra. Ressalta-se que a importância desse parâmetro é justificada pelo fato de que as cargas do adsorvato e do adsorvente devem ser opostas para que haja maior interação eletrostática entre ambos, de modo a favorecer o processo adsortivo (NASCIMENTO et al., 2014).

Já em relação à densidade destaca-se que os valores desse parâmetro podem apresentar relação com o volume de poros do material, visto que maior volume de poros ocasiona redução da densidade aparente (LEMAN et al., 2017).

O teor de cinzas apresenta relação direta com o teor de matéria inorgânica presente no material, de modo que maiores teores de cinzas remetem a maiores valores de matéria inorgânica. A composição das cinzas varia de acordo com a origem do material precursor. Entretanto, de modo geral, o carvão originado de biomassas lignocelulósicas apresenta teores variando de 0,2 a $9,5 \%$. As cinzas apresentam como característica a redução da capacidade adsortiva do material, visto que o seu caráter hidrofílico adsorve preferencialmente água (LOPES et al., 2013). O teor de umidade representa outro parâmetro de grande importância na análise do carvão ativado, visto que a norma EB-2133 estabelece o valor máximo de 8\% (ABNT, 1991a) para carvões pulverizados, utilizado na adsorção de impurezas no tratamento de água (FISCHER et al., 2019).

De acordo com um estudo conduzido por Fonseca (2013), o carvão ativado com cloreto de zinco de borra de café produzido em cápsula de porcelana obteve valor de $\mathrm{pH}$ médio de 5,34, enquanto o produzido em reator de quartzo obteve valor médio de $\mathrm{pH} 5,25$ no processo. Dessa forma, o carvão ativado produzido em mufla obteve valor superior de $\mathrm{pH}$, quando comparado ao estudo de Fonseca (2013). O mesmo trabalho ressalta que é comum carvão ativado com cloreto de zinco apresentar $\mathrm{pH}$ inferior ao de carvão ativado com hidróxido de potássio.

$\mathrm{O}$ carvão ativado produzido com $\mathrm{ZnCl}_{2}$ também apresenta rendimento superior, quando comparado ao processo de ativação com KOH. O cloreto de zinco produziu carvões com maior rendimento e esse resultado pode ser comparado a estudos semelhantes utilizando diferentes materiais precursores em que o rendimento com o agente $\mathrm{ZnCl}_{2}$ foi superior a 25\% para todos os trabalhos conduzidos (OLIVEIRA, 2008; KARAM, 2011; FONSECA, 2013).

Além disso, outro trabalho, realizado por Youssef, El-Nabarawy e Samra (2004), que produziu carvão ativado a partir de espiga de milho demonstrou que a eficiência do $\mathrm{ZnCl}_{2}$ como agente ativador apresenta-se também na área superficial específica (ASE) do carvão ativado. Os resultados desse estudo mostraram que os carvões ativados com $\mathrm{H}_{2} \mathrm{SO}_{4}$ têm área superficial na ordem de $200 \mathrm{~m}^{2} \mathrm{~g}^{-1}$, enquanto os carvões ativados com $\mathrm{ZnCl}_{2}$ apresentaram área superficial de aproximadamente $700-900 \mathrm{~m}^{2} \mathrm{~g}^{-1}$. Deve-se destacar a relevância da ASE na remoção de corantes de soluções aquosas, em que maiores áreas remetem a maior capacidade de adsorção (COSTA; FURMANSKI; DOMINGUINI, 2015).

Estudo realizado por Barros (2001) apresentou a caracterização para diferentes materiais adsorventes. Dentre eles, destacam-se carvão "schungite" e o carvão ativado comercial. O estudo demonstrou valores de pH de 4,21 e 9,67 para o carvão schungite e para o carvão ativado comercial, respectivamente. Também foram analisados os valores de densidade de cada material no qual o carvão "schungite" obteve valor de $2,36 \mathrm{~g} \mathrm{~cm}^{-3} \mathrm{e}$ o carvão ativado comercial com densidade $1,44 \mathrm{~g} \mathrm{~cm}^{-3}$. Os valores encontrados no estudo descrito se aproximam dos valores apresentados no presente estudo.

Para compreensão das propriedades adsortivas do carvão ativado produzido no presente estudo, foi realizado teste de adsorção para verificar o percentual de remoção dos corantes para os diferentes materiais utilizados na produção do carvão ativado proveniente do caroço de pêssego, em comparação ao carvão ativado granulado comercial. As condições utilizadas foram agitação constante de 120 rpm em 24 horas de ensaio de adsorção (Figura 4).

É possível observar, na Figura 4, que a ativação do material desempenhou importante papel na capacidade adsortiva do carvão ativado, uma vez que essa etapa visa à remoção dos compostos que possam obstruir os poros, promovendo maior eficiência adsortiva do material (NIETO-DELGADO; PARTIDAGUTIERREZ; RANGEL-MENDEZ, 2019). Segundo Alves (2007), o processo de ativação resulta no aparecimento de uma alta ASE no material, com valores variando entre 300 e $2.500 \mathrm{~m}^{2} \mathrm{~g}^{-1}$, responsáveis pelas propriedades adsortivas apresentadas por carvão ativado.

Akçakal, Sahin e Erdem (2018), ao utilizarem ativação química $\left(\mathrm{ZnCl}_{2}\right)$ e física (carbonização) para produção de carvão ativado contendo caroço de pêssego (CA), demonstraram que ocorreu aumento na área superficial e no volume total de poros com o aumento da temperatura de 500 para $700^{\circ} \mathrm{C}$. Quando comparado o carvão ativado comercial com o carvão ativado convencional (CA), este apresentou áreas de superfície e volume total de poros superiores. Assim, tais ativações aumentam a área superficial do caroço de pêssego, consequentemente produzem um carvão ativado microporoso, o que reflete no aumento da capacidade adsortiva dos corantes pelo CA em relação aos in natura e ao carvão do caroço de pêssego apenas carbonizado.

Yan et al. (2018), ao utilizar ácido cítrico para produziu carvão ativado do caroço de pêssego, perceberam que houve aumento na área superficial do material e, por conseguinte, aumento na capacidade adsortiva do corante AM. Embora o tipo de ativação do carvão seja diferente do apresentado na Figura 4, ainda assim houve aumento na remoção do corante $\mathrm{AM}$, uma vez ativado o material.

Quanto aos dados experimentais, esses foram ajustados aos três modelos de curvas cinéticas. Os resultados demonstram que o melhor ajuste para os corantes PR5 e AM foram os modelos Pseudoprimeira ordem e Pseudossegunda ordem, respectivamente. O estudo cinético para o tratamento de efluentes torna-se importante devido aos dados informados sobre o mecanismo do processo de adsorção, como, por exemplo, a quantidade removida em relação ao tempo, sendo de grande relevância na projeção de uma ETE (CRINI; BADOT, 2008; VAGHETTI et al., 2009). A Tabela 2 apresenta os parâmetros e a qualidade do ajuste para a adsorção dos corantes PR5 e AM. 


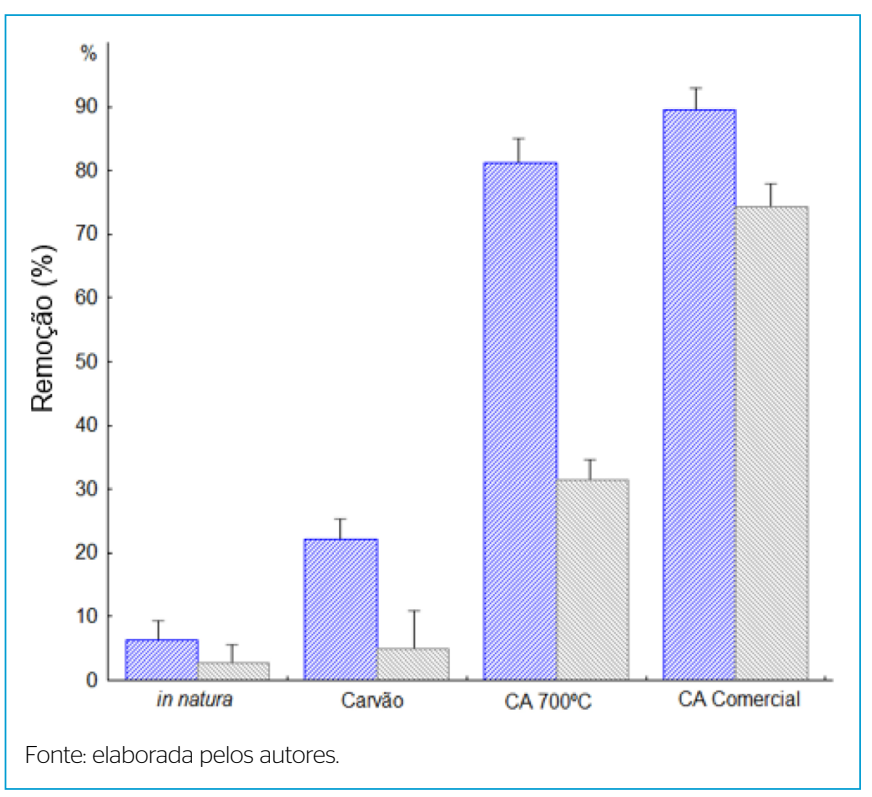

Figura 4 - Percentual de remoção dos corantes AM : e PR5 pelo in natura (caroço de pêssego em natura), Carvão (caroço carbonizado), CA $700^{\circ} \mathrm{C}$ (carvão ativado à $700^{\circ} \mathrm{C}$ ) e CA Comercial (carvão ativado comercial).

Tabela 2 - Parâmetros dos modelos cinéticos para adsorção dos corantes.

\begin{tabular}{|c|c|c|}
\hline Modelos cinéticos & PR5 & AM \\
\hline \multicolumn{3}{|c|}{ Pseudoprimeira ordem } \\
\hline $\mathrm{q} 1\left(\mathrm{~g} \mathrm{gm}^{-1}\right)$ & 45,3951 & 68,3801 \\
\hline $\mathrm{k} 1\left(\min ^{-1}\right)$ & 0,1037 & 0,1607 \\
\hline $\mathrm{R}^{2}$ & 0,9897 & 0,9929 \\
\hline EMR (\%) & 12,6455 & 5,1465 \\
\hline \multicolumn{3}{|c|}{ Pseudossegunda ordem } \\
\hline $\mathrm{q} 2\left(\mathrm{mg} \mathrm{g}^{-1}\right)$ & 57,2120 & 79,7784 \\
\hline $\mathrm{k} 2\left(\mathrm{~min}^{-1}\right)$ & 0,0017 & 0,0023 \\
\hline $\mathrm{R}^{2}$ & 0,9790 & 0,9942 \\
\hline ERM (\%) & 17,4049 & 4,2707 \\
\hline \multicolumn{3}{|l|}{ Elovich } \\
\hline $\mathrm{a}\left(\mathrm{mg} \mathrm{g}^{-1}\right)$ & 0,0634 & 0,0566 \\
\hline$b\left(\operatorname{mg~g}-1 \min ^{-1}\right)$ & 7,0301 & 25,2096 \\
\hline$R^{2}$ & 0,9615 & 0,9801 \\
\hline ERM (\%) & 22,2701 & 6,3275 \\
\hline
\end{tabular}

EMR: erro médio relativo.

Fonte: elaborada pelos autores.

Os valores de $\mathrm{R}^{2}$ e do erro médio relativo (EMR) demonstram o modelo Pseudoprimeira ordem como sendo o que apresentou o melhor ajuste aos dados de cinética de adsorção do corante PR5. Na Figura 5 é demonstrada a adsorção do corante PR5 ajustada ao modelo cinético de Pseudoprimeira ordem.

O ajuste do corante AM ao modelo cinético de Pseudossegunda ordem de menor erro relativo médio está apresentado na Figura 6.

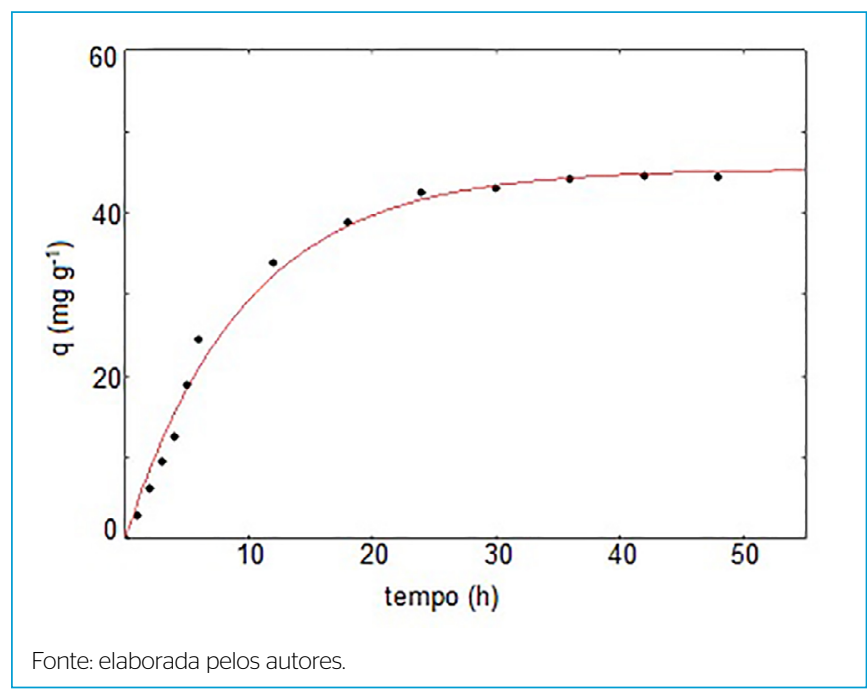

Figura 5 - Dados experimentais da adsorção do corante PR5 ajustados ao modelo cinético Pseudoprimeira ordem $\left(R^{2}=0,9897\right)$.

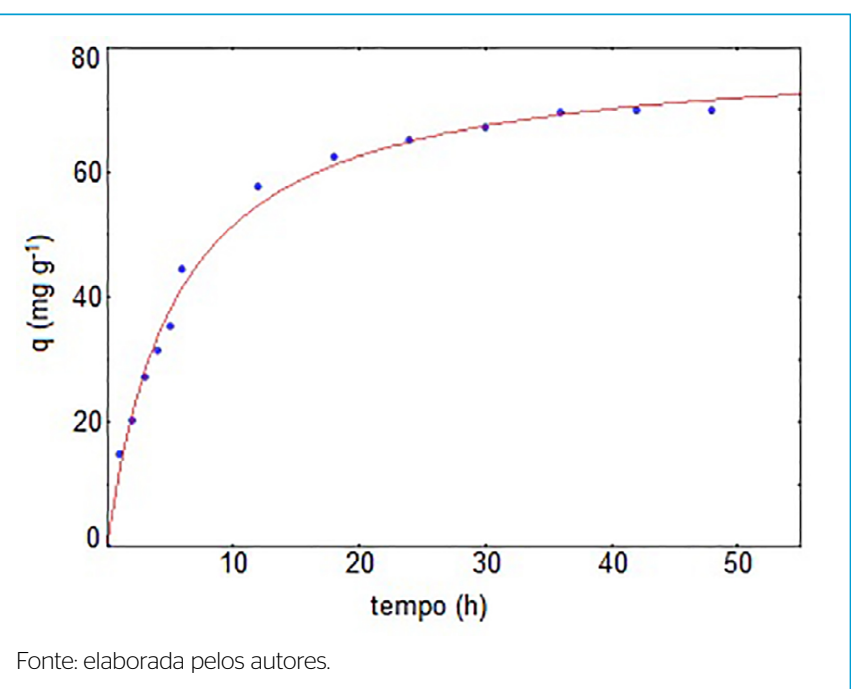

Figura 6 - Dados experimentais da adsorção do corante AM ajustados ao modelo cinético Pseudossegunda ordem $\left(R^{2}=0,9942\right)$.

Um estudo conduzido por Paiva et al. (2015) demonstrou que os resultados dos parâmetros do estudo cinético e os coeficientes de correlação $\left(\mathrm{R}^{2}\right)$ que melhor se ajustaram para o material adsorvente utilizado, bagaço de caju (BC) e BC da produção de xilitol (BCX), também foram de Pseudossegunda ordem e Pseudoprimeira ordem, respectivamente. Entretanto, o estudo conduzido por Cionek et al. (2015) demonstrou que o modelo cinético que melhor representou os dados experimentais da cinética de adsorção do carvão ativado de babaçu foi o de Pseudossegunda ordem.

$\mathrm{Na}$ adsorção do corante $\mathrm{AM}$, diferentes estudos demonstraram em seus resultados que o modelo de Pseudossegunda ordem também foi o de melhor ajuste aos dados experimentais (AUTA; HAMMED, 2014; GUPTA et al., 2014). 
Nesse contexto, quando o modelo cinético de Pseudossegunda ordem representa a cinética, o mecanismo predominante no processo pode ser a adsorção química. O comportamento pode estar relacionado a menor competição para os sítios de adsorção na superfície com concentração mais baixa. Em concentrações mais elevadas, a competição para os sítios ativos da superfície será elevada, consequentemente, menores quantidades de adsorção serão obtidas (NIETO-DELGADO; PARTIDA-GUTIERREZ; RANGEL-MENDEZ, 2019).

Apesar de o processo de adsorção em carvão ativado apresentar eficiência significativamente maior do que outros materiais, a adsorção de corantes de caráter catiônico é fator limitante. A razão dessa limitação se dá devido à carga ser positiva e isso se apresenta independentemente do material adsorvente utilizado (KUNZ et al., 2002). Entretanto, o presente estudo apresentou boa correlação dos dados experimentais ao ajuste dos modelos cinéticos para os dois corantes, especialmente para o AM.

Segundo Crini e Lichtfouse (2019), para o alcance da eficiência é necessária a escolha de um adsorvente com alta capacidade, durabilidade, disponibilidade e baixo custo. Nesse aspecto, a adsorção com carvão ativado de caroço de pêssego apresenta-se como alternativa econômica bastante eficaz.

Com relação ao ajuste dos dados experimentais aos modelos de isoterma, o modelo de Freundlich foi o que apresentou o melhor ajuste aos dados experimentais para os dois corantes utilizados no estudo (Tabela 3).

Para o corante PR5, o modelo de isoterma de Freundlich $\left(\mathrm{R}^{2}>0,99\right.$ e $\mathrm{EMR}<0,9 \%$ ) foi o que apresentou o ajuste mais adequado aos dados. Desse modo, o modelo pode ser empregado para representar os dados experimentais, descrever a capacidade de adsorção e também estabelecer as quantidades requeridas. As Figuras 7 e 8 demonstram os valores experimentais obtidos para os corantes empregados (PR5 e AM) ajustados aos modelos de isoterma de Langmuir e Freundlich.

As isotermas para o carvão ativado de coco de babaçu como material precursor, para o tratamento de efluente contendo corante reativo azul BF-5G, foram mais bem ajustadas ao modelo de Freundlich para diferentes faixas de temperatura $\left(20,30\right.$ e $\left.40^{\circ} \mathrm{C}\right)$ (CIONEK et al., 2015). O mesmo ajuste foi obtido no estudo realizado por Rocha (2006), ao utilizar endocarpo da

Tabela 3 - Parâmetros de isoterma de Langmuir e Freundlich e coeficientes de ajuste para adsorção dos corantes PR5 e AM pelo carvão ativado.

\begin{tabular}{|c|c|c|}
\hline Isotermas & PR5 & $\mathrm{AM}$ \\
\hline \multicolumn{3}{|l|}{ Langmuir } \\
\hline $\mathrm{q}_{\max }\left(\mathrm{mg} \mathrm{g}^{-1}\right)$ & 73,183 & 50,119 \\
\hline $\mathrm{bx} 10^{3}\left(\mathrm{~L} \mathrm{mg}^{-1}\right)$ & 0,073 & 0,012 \\
\hline$R^{2}$ & 0,974 & 0,963 \\
\hline EMR (\%) & 1,791 & 4,325 \\
\hline \multicolumn{3}{|l|}{ Freundlich } \\
\hline $\mathrm{K}_{\mathrm{F}}\left[\left(\mathrm{mg} \mathrm{g}^{-1}\right)\left(\mathrm{L} \mathrm{mg}^{-1}\right)^{1 / n}\right]$ & 18,389 & 2,248 \\
\hline $\mathrm{n}$ & 3,631 & 1,863 \\
\hline$R^{2}$ & 0,992 & 0,993 \\
\hline EMR (\%) & 0,924 & 1,877 \\
\hline
\end{tabular}

EMR: erro médio relativo.

Fonte: elaborada pelos autores. macadâmia ativado com cloreto de zinco e carbonizado para tratamento de efluentes contendo cobre, ou seja, embora os materiais precursores nos estudos sejam diferentes do carvão ativado do caroço de pêssego, o processo de ativação é similar e o modelo de melhor ajuste foi o de Freundlich, sob condições semelhantes.

De acordo com Paiva et al. (2015), a equação de Freundlich é uma equação empírica usada para descrever sistemas heterogêneos e de adsorção reversível, que não se restringe à formação da monocamada. Enquanto, a isoterma de Langmuir é aplicável aos sistemas de adsorção homogêneos.

Como já proposto, a isoterma de Freundlich é utilizada para sistemas heterogêneos com interação entre as moléculas adsorvidas. De acordo com o parâmetro $1 / \mathrm{n}$, conforme pode ser observado na Tabela 3, quanto maior o valor de $1 / n$, maior a tendência ao ajuste de Freundlich. Nota-se que o valor de n próximo

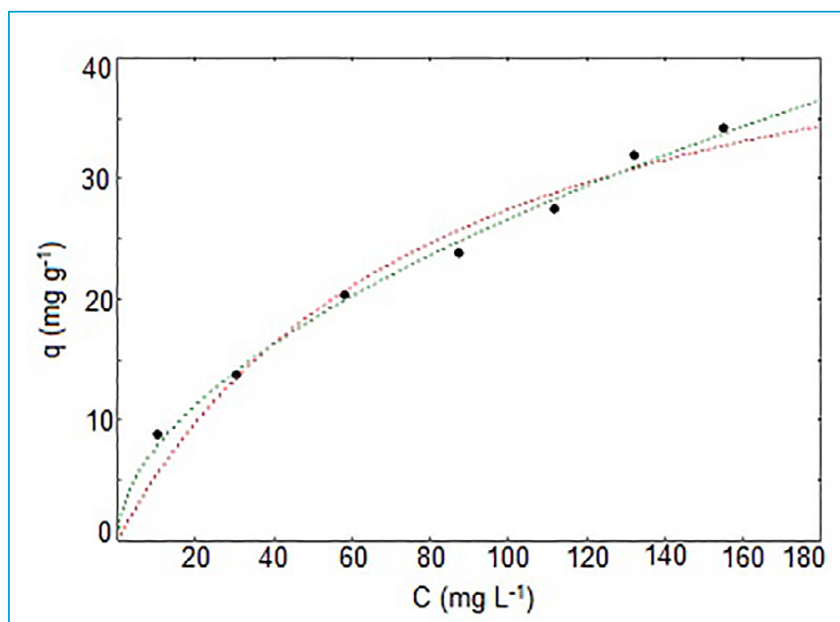

Fonte: elaborada pelos autores.

Figura 7 - Dados experimentais da adsorção do corante PR5 ajustados ao (…… Modelo de Isoterma Langmuir e ( $\cdots$.... $)$ Modelo de Isoterma Freundlich $\left(\mathrm{T}=25^{\circ} \mathrm{C}\right)$.

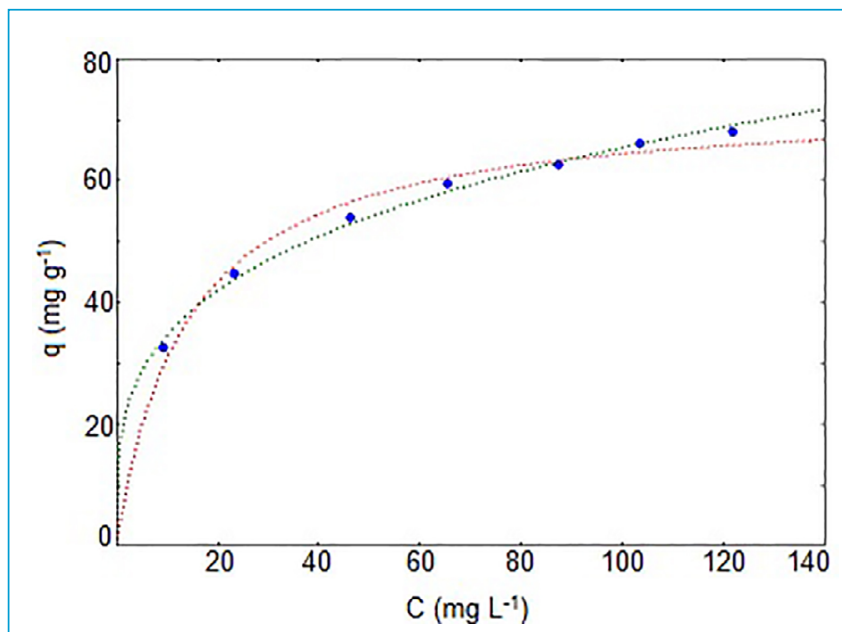

Fonte: elaborada pelos autores

Figura 8 - Dados experimentais da adsorção do corante AM ajustados ao (…...) Modelo de Isoterma Langmuir e $(\cdots \cdots)$ Modelo de Isoterma Freundlich $\left(\mathrm{T}=25^{\circ} \mathrm{C}\right)$. 
de 1 indica forte afinidade. Essa forte afinidade permite inferir que a saturação do adsorvente ainda não está próxima e que, portanto, em uma solução de maior concentração inicial, a capacidade de adsorção pode ser ainda maior.

É importante ressaltar que a principal diferença entre esses dois modelos é que Freundlich não prevê a saturação do adsorvente. Portanto, os resultados evidenciados pelo modelo de Freundlich apresentam boa descrição dos equilíbrios obtidos, os quais demonstram os maiores coeficientes de correlação.

Com relação ao tratamento de efluente com o carvão ativado, é possível observar, no comportamento do espectro de absorção, a remoção de cor do efluente têxtil pelo carvão ativado produzido de caroço de pêssego (Figura 9). Os resultados demonstraram diminuição da intensidade de absorção no efluente tratado.

Os resultados de eficiência para a remoção de cor no efluente têxtil (efluente real) para o comprimento de onda $\lambda=665 \mathrm{~nm}$ (AM) e $\lambda=598 \mathrm{~nm}$ (PR5) utilizados para os corantes empregados no presente estudo demonstram ser 59,14\% para AM e de 63,69\% para PR5 no efluente têxtil, sendo a eficiência média do processo completo de remoção da cor do efluente superior a $62 \%$. Os valores de eficiência de remoção dos corantes PR5 e AM em solução encontrados no presente estudo foram de 56,60 e $86,75 \%$, respectivamente. Dessa forma, o resultado encontrado para remoção da coloração do efluente têxtil apresenta-se próximo aos valores obtidos para o estudo com os corantes após 24 horas de processo.

Os corantes normalmente são recalcitrantes, ou apresentam cinética muito lenta diante de processos de tratamentos biológicos convencionais, resultando, ao final do tratamento, em efluentes com coloração ainda muito intensa (CRINI; LICHTFOUSE, 2019). Se a coloração dos efluentes do tingimento pudesse ser totalmente eliminada, por meio de um processo eficiente de adsorção, estes poderiam ser reutilizados para outros processos, como enxágues, limpeza ou

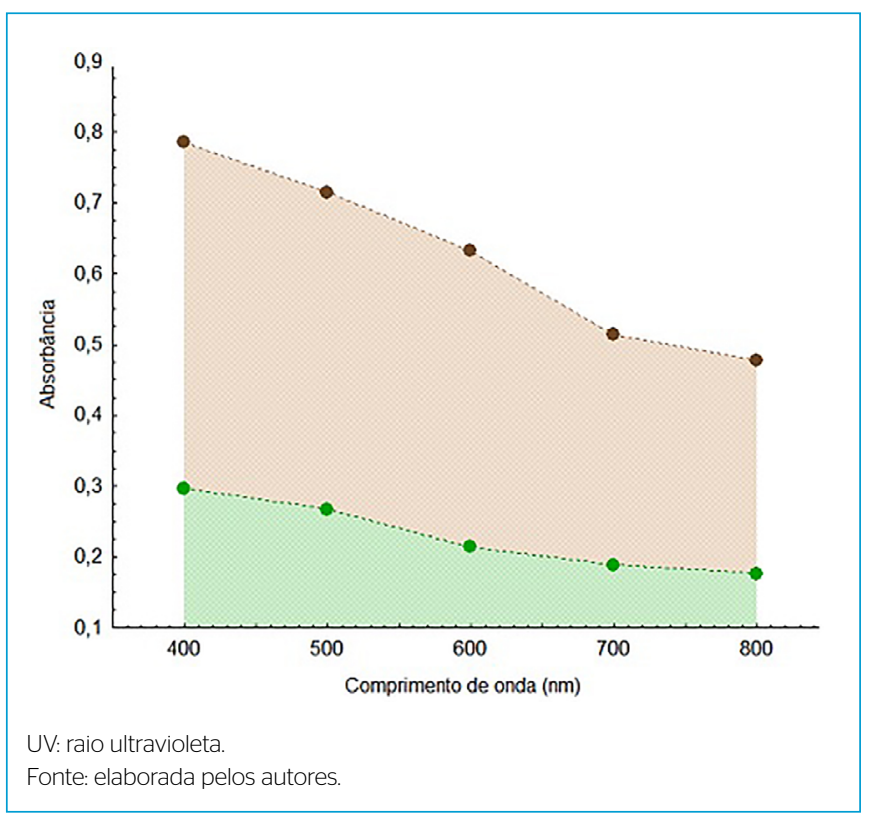

Figura 9 - Espectros de absorção UV-Visível para efluente têxtil: - Efluente Bruto; - Efluente Tratado com carvão ativado de caroço de pêssego após $24 \mathrm{~h}$ que foram mantidos sob agitação constante. tingimento, com consequência na economia de consumo de água da indústria (QUADROS, 2005).

O uso da adsorção com carvão ativado, como método de tratamento de efluentes contendo corantes, tem sido interesse de diferentes pesquisadores. Entretanto, o caráter de especificidade entre adsorbato e adsorvente leva à necessidade de ampliação de estudos com aplicação em efluentes reais. Ainda assim, o carvão ativado produzido com caroços de pêssego apresentou eficiente remoção da coloração no efluente têxtil, demonstrando, assim, que essa alternativa poderia ser empregada no aproveitamento de água para os demais processos dentro da indústria, embora não se tenha realizado estudos de isoterma para o efluente têxtil.

\section{CONCLUSÃO}

O presente estudo analisou o potencial da utilização de caroço de pêssego como material precursor para a produção de carvão ativado. Os resultados se demonstraram positivos para a produção do carvão ativado bem como da caracterização que se apresentou próximas às características de outros estudos. Com relação à metodologia de superfície de resposta, os resultados demonstram que a melhor temperatura para o processo de carbonização é de $700^{\circ} \mathrm{C}$ e que o melhor tempo empregado no processo é de $10 \mathrm{~min}$

A amostra de carvão ativado a $700^{\circ} \mathrm{C}$ apresentou índice superior a $93 \%$ de eficiência na adsorção do corante AM e valor de aproximadamente de $60 \%$ de eficiência na adsorção do corante PR5. Isso caracteriza amplo potencial de utilização, mas com eficiência maior na adsorção do corante AM.

Os resultados do teste de adsorção do carvão foram muito satisfatórios e próximos dos valores alcançados pelo carvão ativado granulado comercial. Sobre a cinética de adsorção, o modelo de melhor ajuste foi o modelo de Pseudoprimeira ordem para o corante PR5 e o modelo cinético de Pseudossegunda ordem para o corante AM. Entretanto, para o ajuste dos dados experimentais aos modelos de isoterma, o modelo de Freundlich apresentou-se com o melhor ajuste para ambos os corantes utilizados no estudo.

O carvão ativado apresentou bons resultados quanto à capacidade de adsorção da cor, para a maioria dos corantes presentes, no tratamento de efluentes provenientes da indústria têxtil. Dessa forma, os resultados obtidos no presente estudo indicam que o resíduo apresenta elevado potencial na produção de carvões ativados para uso no tratamento de efluentes contendo corantes, bem como proporciona interesse econômico na transformação de um problema ambiental - resíduo de caroço de pêssego - em um produto com alto valor econômico agregado, como o carvão ativado produzido a partir de uma fonte renovável.

\section{CONTRIBUIÇÕES DOS AUTORES}

Demarco, C. F.: Validação, Visualização, Escrita — Primeira Redação. Andreazza, R.: Conceituação, Curadoria de Dados, Análise Formal, Obtenção de Financiamento, Investigação, Metodologia, Administração do Projeto, Recursos, Software, Supervisão, Validação, Visualização, Escrita - Primeira Redação. Lopes, B. V.: Conceituação, Curadoria de Dados, Análise Formal. Afonso, T. F.: Conceituação, Curadoria de Dados, Análise Formal. Cadaval Junior, T. R.: Análise Formal. Quadro, M. S.: Escrita - Primeira Redação. Heylmann, K. K. A.: Escrita Primeira Redação. 


\section{REFERÊNCIAS}

AHMADPOUR., D.D.D. The preparation of active carbons from coal by chemical and physical activation. Carbon, v. 34, n. 4, p. 471-479, 1996. https:// doi.org/10.1016/0008-6223(95)00204-9

AKÇAKAL, O.; SAHIN, M.; ERDEM, M. Synthesis and characterization of highquality activated carbons from hard-shelled agricultural wastes mixture by zinc chloride activation. Chemical Engineering Communications, v. 206, n. 7. p. 888-897, 2018. https://doi.org/10.1080/00986445.2018.1534231

ALVES, A.C.M. Avaliação do tratamento de efluentes líquidos contendo cobre e chumbo por adsorção em carvão ativado. Dissertação (Mestrado) - Programa de Pós-Graduação em Recursos Hídricos e Saneamento, Universidade Federal de Alagoas, Maceió, 2007.

AOAC. Official methods of analysis. 16. ed. Aitherburg: AOAC International, 1997. v. 2.

ASSOCIAÇÃO BRASILEIRA DE NORMAS TÉCNICAS (ABNT). Carvão ativado pulverizado - Especificação - EB-2133. Rio de Janeiro: ABNT, 1991a.

ASSOCIAÇÃO BRASILEIRA DE NORMAS TÉCNICAS (ABNT). NBR 12075 : carvão ativado pulverizado - Determinação granulométrica - Método de ensaio. Rio de Janeiro: ABNT, 1991b. Disponível em: https://www. abntcatalogo.com.br/norma.aspx?|D=005711. Acesso em: jun. 2019 .

AUTA, M.; HAMEED, B.H. Chitosan-clay composite as highly effective and low-cost adsorbent for batch and fixed-bed adsorption of methylene blue. Chemical Engineering Journal, v. 237, n. 2, p. 352-361, 2014. https://doi. org/10.1016/j.cej.2013.09.066

BARROS, A.R.B. Remoção de íons metálicos em água utilizando diversos adsorventes. Dissertação (Mestrado) - Programa de Pós-Graduação em Engenharia Química, Centro Tecnológico, Universidade Federal de Santa Catarina, Florianópolis, 2001.

CIONEK, C.A.; CARVALHO, D.S.; BARROS, M.A.S.D; ARROYO, P.A. Avaliação de carvão ativado de babaçu para a adsorção seletiva de corante reativo BF-5G. In: CONGRESSO BRASILEIRO DE ENGENHARIA QUIIMICA, 20., 2015. Anais [...]. v. 1, n. 2, p. 1-8, 2015. http://doi.org/10.5151/chemeng-cobeq2014-0338-25943-164426

COSTA, P.D.D.; FURMANSKI, L.M.; DOMINGUINI, L. Production, Characterization and Application of Activated Carbon from Nutshell for Adsorption of Methylene Blue. Revista Virtual de Química, v. 7. n. 4, p. 1272-1285, 2015. https://doi.org/10.5935/1984-6835.20150070

CRINI, G.; BADOT,P.M. Application of chitosan, a natural aminopolysaccharide, for dye removal from aqueous solutions by adsorption processes using batch studies: A review of recent literature. Progress in Polymer Science, v. 33, n. 4, p. 399-447, 2008. https://doi.org/10.1016/j.progpolymsci.2007.11.001

CRINI, G.; LICHTFOUSE, E. Advantages and disadvantages of techniques used for wastewater treatment. Environmental Chemistry Letters, v. 17, n. 1 , p. 145-155, 2019. https://doi.org/10.1007/s10311-018-0785-9

DENG, H.; LU, J.; LI, G.; ZHANG, G.; WANG, X. Adsorption of methylene blue on adsorbent materials produced from cotton stalk. Chemical Engineering Journal, v. 172, n. 1, p. 326-334, 2011. https://doi.org/10.1016/j.cej.2011.06.013

DUFOURNY, A.; STEENE, L.V.D.; HUMBERT, G.; GUIBAL, D.; MARTIN, L.; BLIN, J. Influence of pyrolysis conditions and the nature of the wood on the quality of charcoal as a reducing agent. Journal of Analytical and Applied Pyrolysis, v. 137, p. 1-13, 2019. https://doi.org/10.1016/j.jaap.2018.10.013

FISCHER, H.C.V.; LIMA, L.S.D.; FELSNER, M.L.; QUINAIA, S.P. Estudo da capacidade de adsorção de carvões ativados comerciais versus tempo de armazenamento Ciência Florestal, v. 29, n. 3, p. 1090-1099, 2019. https://doi org/10.5902/1980509838092

FONSECA, A.C.C. Produção de carvão ativado utilizando como precursor borra de café e sua aplicação na adsorção de fenol. 50f. Trabalho de Conclusão de Curso (Graduação) - Universidade Tecnológica Federal do Paraná, Curitiba, 2013.

GONÇALVES, M.; GUERREIRO, M.C.; BIANCHI, M.L.; OLIVEIRA, L.C.A.; PEREIRA, E.I.; DALLAGO, R.M. Produção de carvão a partir de resíduo de erva-mate para a remoção de contaminantes orgânicos de meio aquoso. Ciência e Agrotecnologia, v. 31, n. 5, p. 1386-1391, 2007. https://doi.org/10.1590/ S1413-70542007000500017

GUILLOSSOU, R.; LE ROUX, J.; MAILLER, R.; VULLIET, E.; MORLAY, C.; NAULEAU, F.; GASPERI, J.; ROCHER, V. Organic micropollutants in a large wastewater treatment plant: what are the benefits of an advanced treatment by activated carbon adsorption in comparison to conventiona treatment? Chemosphere, v. 218, p. 1050-1060, 2019. https://doi.org/10.1016/j. chemosphere.2018.11.182

GUPTA, V.K.; PATHANIA, D.; SINGH, P.; KUMAR, A.; RATHORE, B.S. Adsorption removal of methylene blue by guar gum-cerium (IV) tungstate hybrid cationic exchanger. Carbohydrate Polymers, v. 101, p. 684-691, 2014. https:// doi.org/10.1016/j.carbpol.2013.09.092

GÜRSES, A. Natural products in adsorption technology. In: SHAHID-UL, I. (org.). Integrating green chemistry and sustainable engineering. Estados Unidos: Scrivener, 2019. p. 397-441.

INSTITUTO BRASILEIRO DE GEOGRAFIA E ESTATISTICA (IBGE). Produção Agrícola anual: tabela 5457. IBGE. Disponível em: https://sidra.ibge.gov.br/ tabela/5457\#resultado. Acesso em: jun. 2019

ISO. DIN EN ISO 7887. Water Quality - Examination and determination of Colour. ISO, 1994.

JAHNKE, J.C:; HORNBUCKLE, K.C. PCB Emissions from paint colorants Environmental Scicence Technology, v. 53, n. 9, p. 5187-5194, 2019. https:// doi.org/10.1021/acs.est.9b01087

KAMMRADT, P.B. Remoção de cor de efluente de tinturarias industriais através de processo de oxidação avançada. Dissertação (Mestrado) Programa de Pós-Graduação em Engenharia de Recursos Hídricos e Ambiental, Departamento de Hidráulica e Saneamento, Universidade Federal do Paraná, Curitiba, 2004.

KARAM, B.C.D. Produção e caracterização de carvões ativados (CA) de biomassa amilácea pirolisados em forno de microondas. Trabalho de Conclusão de Curso (Graduação) - Universidade Tecnológica Federal do Paraná, Curitiba, 2011.

KOSHELEVA, R.I; MITROPOULOS, A.C.; KYZAS, G.Z. Synthesis of activated carbon from food waste. Environmental Chemistry Letters, v. 17, p. 429-438, 2019. https://link.springer.com/article/10.1007/s10311-018-0817-5 
KUNZ, A.; PERALTA-ZAMORA, P.; MORAES, S.G.; DURÁN, N. Novas tendências no tratamento de efluentes têxteis. Química Nova, v. 25, n. 1, p. 78-82, 2002. https://doi.org/10.1590/S0100-40422002000100014

LEMAN, A.M.; ZAKARIA, S.; SALLEH, M.N.M.; SUNAR, N.M.; FERIYANTO, D.; NAZRI, A.A. The effect of activation agent on surface morphology, density and porosity of palm shell and coconut shell activated carbon. In: ELECTRONIC AND GREEN MATERIALS INTERNATIONAL CONFERENCE, 3., 2017. Anais [...]. v. 1885, p. 020001, 2017.

LOPES, C.W.; BERTELLA, F.; PERGHER, S.B.C.; FINGER, P.H.; DALLAGO, R.M.; PENHA, F.G. Synthesis and characterization of activated carbons derived from corn cob. Perspectiva, v. 37, n. 139, p. 27-35, 2013.

NASCIMENTO, R.F.D.; LIMA, A.C.A.D.; VIDAL, C.B.; MELO, D.D.Q.; RAULINO, G.S.C. Adsorção: aspectos teóricos e aplicações ambientais. Fortaleza: Imprensa Universitária UFC, 2014.

NIEDERSBER, C. Ensaios de adsorção com carvão ativado produzido a partir da casca do tungue (Aleurites Fordii), resíduo do processo de produção de óleo. Dissertação (Mestrado em Tecnologia Ambiental) Universidade de Santa Cruz do Sul, Santa Cruz do Sul, 2012.

NIETO-DELGADO, C.; PARTIDA-GUTIERREZ, D; RANGEL-MENDEZ, J.R. Preparation of activated carbon cloths from renewable natural fabrics and their performance during the adsorption of model organic and inorganic pollutants in water. Journal of Cleaner Production, v. 213, n. 3, p. 650-658, 2019. https://doi.org/10.1016/j.jclepro.2018.12.184

ODUBIYI, O.A.; AWOYALE, A.A.; ELOKA-EBOKA, A.C. Waste water treatment with activated charcoal produced from Cocoa pod husk. International Journal Environment Bioenergy, v. 4, n. 3, p. 162-175, 2012.

OLIVEIRA, M.P. Obtenção, caracterização e aplicações de carvão ativado a partir de caroços de pêssegos. Tese (Doutorado) - Universidade Federal de Pelotas, Pelotas, 2008.

PAIVA, L.A.; SILVA, N.C.G.; ALBUQUERQUE, T.L.; SILVA, R.; ROCHA, M.V.P. Estudo do aproveitamento do bagaço de caju residual da produção de xilitol como adsorvente do corante Reativo Azul BF-R. In: CONGRESSO BRASILEIRO DE ENGENHARIA QUIIMICA, 1., 2015. Anais [...]. n. 2, p. 82698276, 2015. https://doi.org/10.5151/chemeng-cobeq2014-1138-20792-155114

QUADROS, S.S. Tratamento e reutilização de efluentes têxteis gerados nos tingimentos de tecidos de algodão. Dissertação (Mestrado) - Programa de Pós-Graduação em Química, Centro de Ciências Exatas e Naturais, Universidade Regional de Blumenau, Blumenau, 2005.

ROCHA, W.D.; LUZ, J.A.M.; LENA, J.C.; BRUÑA-ROMERO, O. Adsorção de cobre por carvões ativados de endocarpo de noz de macadâmia e de semente de goiaba. Revista Escola de Minas, v. 59, n. 4, p. 409-414, 2006. https://doi.org/10.1590/SO370-44672006000400010

RUIZ, B.; FERRERA-LORENZO, N.; FUENTE, E. Valorisation of lignocellulosic wastes from the candied chestnut industry. Sustainable activated carbons for environmental applications". Journal of Environmental Chemical Engineering, v. 5, n. 2, p. 1504-1515, 2017. https://doi.org/10.1016/j. jece.2017.02.028

VAGHETTI, J.C.P.; LIMA, E.C.; ROYER, B.; CARDOSO, N.F; MARTINS, B. CALVETE, T. Pecan nutshell as biosorbent to remove toxic metals from aqueous solution. Separation Science and Technology, v. 44, n. 3, p. 615644, 2009. https://doi.org/10.1080/01496390802634331

VISWANATHAN, N.; PERIYASAMY, S.; KUMAR, I.A. Efficient removal of aqueous aromatic pollutants by various techniques. In: NAUSHAD, M. (org.). A New Generation Material Graphene: Applications in Water Technology. Cham: Springer, 2019. p. 261-285. https://doi.org/10.1007/978-3-319-75484-0_11

YAN, J.; LAN, G.; QIU, H.; CHEN, C.; LIU, Y.; DU, G.; ZHANG, J. Adsorption of heavy metals and methylene blue from aqueous solution with citric acid modified peach stone. Separation Science and Technology, v. 53, n. 11, p. 1678-1688, 2018. https://doi.org/10.1080/01496395.2018.1439064

YOUSSEF, A.M.; EL-NABARAWY, T.H.; SAMRA, S.E. Sorption properties of chemically-activated carbons 1.sorption of cadmium (II) ions. Colloids and Surfaces A Physicochemical and Engineering Aspects, v. 235, n. 1-3, p. 153163, 2004. https://doi.org/10.1016/j.colsurfa.2003.12.017 